Nederlandse Taalkunde

www.nederlandsetaalkunde.nl

Uitgave: Amsterdam University Press

\title{
Over werkwoordalternanties in de Syntax of Dutch
}

\author{
Timothy Colleman
}

NT 21 (2): 241-252

DOI: 10.5117/NEDTAA2016.2.COLL

\section{Abstract \\ On verb frame alternations in the Syntax of Dutch}

This review article offers a critical discussion of the extensive treatment of verb frame alternations in the first volume on Verbs and Verb Phrases of the Syntax of Dutch $(S o D)$. The article takes a usage-based perspective and focuses on a number of aspects of the grammatical description in the SoD that are too exclusively rooted in the theoretical framework of formal syntax.

Keywords: verb frame alternations, productivity, usage-based perspective, argument structure constructions, Syntax of Dutch

\section{$1 \quad$ Inleiding}

Het eerste van de drie delen over het werkwoord en de verbale constituent in de Syntax of Dutch (in wat volgt: SoD) besluit met een lijvig hoofdstuk over verbale alternanties (hoofdstuk 3, Broekhuis, Corver \& Vos 2015: 401595), waarin - aansluitend bij het hoofdstuk over argumentstructuur, dat een grofmazige indeling had gepresenteerd van de Nederlandse werkwoorden naar gelang van het aantal en de types van argumenten waarmee ze voorkomen (intransitieve, transitieve, onaccusatieve, NOM-DAT-werkwoorden, enz.) - uitgebreid wordt ingegaan op werkwoorden die met verschillende constellaties van argumenten voorkomen. De auteurs onderscheiden twee hoofdtypes van alternanties: na een korte inleidende paragraaf, volgt eerst een uitgebreide paragraaf over een aantal fenomenen die primair te maken hebben met demotie, weglating of toevoeging van een extern argument: diverse subtypes van passief- en medialisconstructies en de zgn. causatief-inchoatiefalternantie (Jan breekt de vaas vs. De vaas breekt) (pp. 
407-514). De derde paragraaf behandelt het tweede grote hoofdtype, nl. variatie in de realisering van een (intern) argument als nominale dan wel prepositionele constituent: daaronder valt het bekende fenomeen van de datiefalternantie (Jan geeft Piet een boek vs. Jan geeft een boek aan Piet), maar bijvoorbeeld ook de variatie tussen de nominale of prepositionele realisering van het enige interne argument bij werkwoorden als schieten (Jan schiet een konijn vs. Jan schiet op een konijn) (pp. 514-591). Tot slot is er nog een korte paragraaf waarin een aantal schijnbare alternanties aan bod komen (pp. 591-595). Het hoofdstuk levert een belangrijke nieuwe bijdrage aan de grammaticale beschrijving van het Nederlands: weliswaar is er al een aantal studies van afzonderlijke alternanties beschikbaar, maar een synthetiserend overzicht van deze omvang ontbrak tot nog toe - de enige bestaande aanzet daartoe is Van Hout (1996: 39-79), dat echter in veel minder detail ingaat op de gesignaleerde alternanties. Het laat zich dan ook aanzien dat de beschrijving in de $S o D$ de komende jaren een belangrijk referentiepunt zal worden in het onderzoek naar verbale alternanties.

Dat wil uiteraard niet zeggen dat op die beschrijving niets af te dingen valt. Zoals elk naslagwerk van een zekere omvang, bevat ook de SoD een aantal kleine foutjes en onnauwkeurigheden. Voor het hoofdstuk dat hier ter discussie ligt, kan bijvoorbeeld worden verwezen naar p. 446, waar vertellen zowel is opgenomen in de lijst van communicatiewerkwoorden die in het krijgen-passief kunnen voorkomen als in de lijst van werkwoorden waarbij die constructie niet mogelijk is, of naar p. 518, waar in de tabel onder (325) de essentie van de verb sensitive-benadering van Rappaport Hovav \& Levin (2008) verkeerd wordt samengevat: in combinatie met throw-werkwoorden drukt de dubbelobjectconstructie niet caused motion of caused possession uit, maar, cruciaal, enkel caused possession. Het zou echter bepaald kleinzielig zijn om de auteurs, die een titanenwerk hebben verricht waarmee de taalkundige neerlandistiek nog decennialang zijn voordeel zal kunnen doen, af te rekenen op de kleine onzorgvuldigheden die een werk van een dergelijke omvang onvermijdelijk binnensluipen. Ik wil het daarom in het vervolg van dit commentaarstuk hebben over een aantal bredere kwesties.

De $S o D$ is wel een descriptieve maar geen theorieneutrale grammatica: zowel in de keuze van de behandelde subtopics en de ordening daarvan als in de bestaande literatuur die wel en niet is verwerkt, toont zich duidelijk de aanhorigheid van de auteurs bij het formele paradigma. Dat wordt in de inleiding tot de hele reeks trouwens ook duidelijk zo gesteld: de algemene doelstelling is om een uitgebreide beschrijving te bieden '[that] also includes the results of the formal linguistic research carried out over the 
last four or five decades that often cannot be found in the existing reference books' (Broekhuis, Corver \& Vos 2015: vii) - of, zoals het in Broekhuis (2013: 245) wordt geformuleerd, de SoD zoekt 'aansluiting bij de meer op theorievorming gerichte, formele taalwetenschap zoals die in de laatste vijftig jaar gestalte heeft gekregen, met een bijzondere nadruk op de verschillende vormen van generatieve grammatica'. Uiteraard wordt er ook buiten de generatieve grammatica aan grammaticale theorievorming gedaan: in functionele en cognitieve, inclusief constructiegrammaticale, benaderingen hebben verbale alternanties al bijzonder veel aandacht genoten, niet in de laatste plaats omdat ze een mooie uitdaging vormen voor de hypothese dat met een verschil in vorm in principe ook een verschil in betekenis correspondeert, die op zijn minst sinds Bolinger (1977) wijdverspreid is binnen het cognitief-functionele paradigma. Die omvangrijke literatuur blijft in de $S o D$ vrijwel volledig buiten beeld en daardoor zijn een aantal relevante inzichten over de behandelde fenomenen gemist. Hieronder bespreek ik kort drie aspecten waarin de beschrijving van verbale alternanties in de $S o D$ - vanuit mijn eigen constructiegrammaticale en dus evenmin theorieneutrale perspectief - voor aanvulling en/of verbetering vatbaar is.

\section{Van syntactische derivatie, en van regelmatigheid vs. idiosyncrasie}

Op een paar plaatsen in hoofdstuk 3 is de grammaticale beschrijving duidelijk gebaseerd op de aanname dat de twee leden van een paar van alternerende constructies derivationeel aan elkaar gerelateerd zijn. Dat is bijvoorbeeld zo in de beschrijving van het zgn. krijgen-passief (d.w.z. de constructie in Hij krijgt die boeken aangeboden, Ze kreeg de prijs overhandigd, enz.), die teruggaat op Broekhuis \& Cornips (1994, 2012). De SoD beklemtoont vooral de regelmatigheid van het krijgen-passief: krijgen-passivering is een productieve syntactische regel, die elke actieve zin met een direct en een indirect object kan omzetten naar de constructie met krijgen zolang aan twee algemene condities is voldaan, nl. (i) het werkwoord moet de wijze van overdracht ('mode of transmission') specificeren (vandaar dat het niet lukt met bv. het algemene overdrachtswerkwoord geven) en (ii) het indirect object moet een ontvanger/doel benoemen, geen bron (vandaar dat het niet lukt met bv. ontnemen) (zie p. 451). Met die voorstelling neemt de $S o D$ stelling in tegen analyses waarin het krijgen-passief wordt weggezet als een dermate idiosyncratisch fenomeen dat het niet in aan- 
merking komt voor een grammaticale beregeling. Van de weeromstuit wordt de complexiteit van de (semantische) restricties op de constructie met krijgen echter nogal onderschat: zo wordt, om maar een voorbeeld te noemen, op p. 449 het voorbeeld Hij kreeg de belasting kwijtgescholden aangehaald om te bewijzen dat ook bij de (in het Standaardnederlands erg weinige) werkwoorden waarbij het nominaal indirect object een belanghebbende noemt krijgen-passivering mogelijk is. Ik laat in het midden of kwijtschelden terecht als voorbeeld van een werkwoord met een belanghebbende als indirect object wordt gepresenteerd, maar in elk geval kan worden geobserveerd dat bij allerlei semantisch verwante werkwoorden uit de attitudinele sfeer de krijgen-constructie niet goed mogelijk is: bv. gunnen, misgunnen, benijden, verwijten, kwalijk nemen, enz. Ook kan in dit verband worden gewezen op werkwoorden als kopen, bakken, bestellen, zoeken, breien, enz., die hoewel ze in het verzorgde supraregionale Belgische Nederlands probleemloos kunnen worden ingevuld in de dubbelobjectconstructie (zie daarover Colleman 2010), zich in die variëteit toch niet lenen tot de krijgen-constructie: *... dat hij een cadeautje kreeg gekocht, *... dat ik een eitje kreeg gebakken, enz. Het enige voorbeeld dat overeind blijft is inschenken: dat is een werkwoord met een benefactief IO waarbij de krijgen-constructie inderdaad mogelijk is, zoals overigens ook in Colleman (2010) al werd geobserveerd - een observatie die ik daar in verband breng met het feit dat werkwoorden als inschenken en opscheppen, in tegenstelling tot kopen en de andere hierboven genoemde werkwoorden, gebeurtenissen benoemen waarbij in het typische geval de voorbereidende handeling en de beoogde overdracht naadloos in elkaar overvloeien. Al bij al is het empirische bewijs voor de observatie van de $S o D$ dat krijgen-passivering ook kan worden toegepast op actieve dubbelobjectzinnen met een indirect object dat een belanghebbende noemt dus mager: de zaak lijkt een stuk complexer te liggen dan dat.

Aan de andere kant zijn er geattesteerde gebruikswijzen van de krijgenconstructie die niet kunnen worden teruggevoerd op een actieve dubbelobjectzin. De SoD haalt op p. 450 zelf het type Hij krijgt de hond op zich afgestuurd aan, waarvan de actieve tegenhanger *Ik stuur hem de hond op zich af inderdaad onmogelijk is. De auteurs zien dat niet als problematisch voor een derivationele analyse van het krijgen-passief: ze wijzen erop dat de corresponderende actieve zin strijdig is met condities op de binding van zwakke reflexieven, zodat de redenering lijkt te zijn dat die actieve zin om andere, onafhankelijke redenen niet (als oppervlaktevariant) kan verschijnen. Echter, zelfs als die verklaring al zou opgaan voor zinnen met op $X$ af sturen e.d., ze kan in elk geval niet worden ingeroepen voor gevallen als die 
in (1) tot en met (5) hieronder: ook daar is een dubbelobjectparafrase onmogelijk ("iemand iets onderbrengen, *iemand iets toevoeren, *? iemand een proces aanspannen, enz.) en nochtans bevatten ze geen zwak reflexivum.

(1) Het CML heeft sinds 2005 in overleg met de betrokken ondernemers het potje voor Leiden Centraal ondergebracht gekregen.

$<$ www.ondernemersfonds.nl/.../Notulen_adviesraad_16_maart_20093.doc.>

(2) De hartspier krijgt door een vernauwing niet voldoende zuurstof toegevoerd om voldoende het werk te kunnen doen.

$<$ http://mens-en-gezondheid.infonu.nl/ziekten/115697-pijn-aan-hethart.html>

(3) Vorig jaar nog kreeg ze door elf BV's een rechtszaak aangespannen, omdat ze zou tekortschieten in haar inspanningen voor het klimaat. (De Standaard, 7/11/2015)

(4) Ondertussen kan Imschoot doorgaan met Onyewu in de rug, maar hij krijgt een fout tegengefloten. (<hln.be $>$, artikel van 29/03/2008)

(5) Dat leidt tot de absurde situatie dat NTGent met drie miljoen euro één van de hoogste bedragen geadviseerd krijgt, maar toch onder de lijn zit. En dus naast subsidies zou grijpen. (De Standaard, 28/04/ 2016)

De gepaste conclusie lijkt te zijn dat het krijgen-passief een onafhankelijke constructie is die in het hedendaagse taalgebruik ook werkwoorden aantrekt die niet voorkomen in de actieve constructie met een direct en indirect object. Het voorkomen van zinnen als (1) tot en met (5) is te verklaren door analogie: de eerste vier voorbeeldzinnen bevatten partikelwerkwoorden en laat de constructie met krijgen in het reële taalgebruik nu net een sterke voorkeur aan de dag leggen voor zulke werkwoorden, al vanaf haar ontstaan in het begin van de $20^{\text {ste }}$ eeuw. Het lijkt erop dat de constructie vooral in combinatie met partikelwerkwoorden die een soort overdracht benoemen erg productief is en dat het daarbij niet van cruciaal belang is of die werkwoorden wel of niet ook in de dubbelobjectconstructie kunnen voorkomen; het is dan ook maar een kleine stap van, bijvoorbeeld, iets toegekend/ toegedicht/toegediend/ ... krijgen naar iets toegevoerd krijgen. Adviseren kan wel in de dubbelobjectconstructie, maar (5) kan evenmin als (1)-(4) zijn afgeleid van een actieve zin met een IO, want NTGent is niet de ontvanger van het advies (maar het voorwerp ervan). Blijkbaar gelden op de invulling van het IO-slot in dubbelobjectzinnen met adviseren 
andere restricties dan op de invulling van het subject in krijgen-zinnen met hetzelfde werkwoord.

Voor een constructiegrammaticale analyse die de krijgen-constructie ziet als een afzonderlijk opgeslagen argumentstructuurconstructie met haar eigen semantische en syntactische eigenaardigheden, die bovendien onderhevig zijn aan synchrone en diachrone variatie, levert de hierboven geschetste combinatie van productiviteit en idiosyncrasie geen problemen op. Voor een derivationele analyse die het krijgen-passief wil afleiden van de dubbelobjectconstructie wel. Ik verwijs naar Colleman (2015) en Colleman \& Rens (2016) voor een uitvoeriger bespreking van de formele en semantische eigenschappen van het krijgen-passief als onafhankelijke argumentstructuurconstructie, met aandacht voor variatie in de tijd.

\section{$3 \quad$ Van onmogelijke en weinig gebruikelijke combinaties}

Er is in het hoofdstuk over werkwoordalternanties in de $S o D$ veel aandacht voor individuele werkwoorden die zich onttrekken aan een alternantie, dat wil zeggen die niet kunnen voorkomen in één van de twee constructies van een alternerend paar. Zo worden op p. 525 onder meer benijden, besparen, vergeven, verwijten en beletten genoemd als voorbeelden van werkwoorden die wel in de dubbelobjectconstructie voorkomen maar niet in de alternatieve constructie met een aan-groep en wordt op p. 523 gesuggereerd dat voor doneren het omgekeerde geldt. De auteurs maken geregeld gebruik van symbolen als ${ }^{*}$ ? ?? (?), enz. om daarbij voor enige nuancering te zorgen. Echter, die nuancering betreft dan verschillende gradaties van (twijfel over de) ongrammaticaliteit: aan mogelijke verschillen in gebruikelijkheid, dus in (relatieve) frequentie, wordt geen aandacht besteed. Vanuit het gehanteerde formele perspectief is dat een logische keuze: de auteurs willen een competentiegrammatica schrijven, dus wat voor hen telt, is of een of andere structuur mogelijk is - of die structuur in de praktijk van het taalgebruik vaker of minder vaak wordt gerealiseerd dan een alternatieve structuur is dan louter een kwestie van performance. Vanuit een gebruiksgebaseerd perspectief echter is het onderscheid tussen competence en performance veel minder voor de hand liggend: uit allerlei (psycho)linguïstisch onderzoek is al gebleken dat het talige gedrag van sprekers beïnvloed wordt door de relatieve frequenties van allerlei lexicale en grammaticale items, zodat mag worden aangenomen dat tot de informatie over die talige items die zit opgeslagen in het langetermijngeheugen onder andere ook informatie behoort over hun frequentie (zie bv. Bybee 2010, Divjak \& Gries 
2012, etc.). Dat betekent dat in een gebruiksgebaseerde benadering niet alleen observaties over werkwoorden die in het geheel niet in een van de twee constructies voorkomen relevant zijn: daarnaast kunnen relevante inzichten over de (semantische) relatie tussen de twee alternerende constructies ook worden afgeleid uit observaties over werkwoorden die in principe in beide constructies kunnen voorkomen maar in de praktijk een duidelijke voorkeur aan de dag leggen voor één van de twee. Bijvoorbeeld: bij de werkwoorden die op p. 525 worden genoemd als voorbeelden van werkwoorden die wél zowel in de dubbelobjectconstructie als met aan mogelijk zijn, zitten onder meer werkwoorden als afstaan, uitreiken en verkopen, die blijkens de corpusdata die worden gerapporteerd in Colleman (2009) veel vaker met aan voorkomen dan met een nominaal indirect object, hoewel het geen twijfel lijdt dat ook die tweede constructie perfect grammaticaal is. Op basis van zulke observaties wordt in het betreffende artikel de hypothese geformuleerd dat het voor de keuze tussen de dubbelobjectconstructie en de aan-constructie onder meer een rol speelt of de spreker de veranderende relatie tussen agens en patiens in de verf wil zetten: daarvoor is de aan-constructie namelijk beter geschikt dan de dubbelobjectconstructie, waarin (ook) het recipiens (en de relaties agens-recipiens en recipiens-patiens) sterk op de voorgrond komt. De verklaring in termen van affectedness die in de $S o D$ naar voren wordt geschoven (in de betekenis van de dubbelobjectconstructie zit een abstract predikaat BE AFFECTED BY dat in de aan-constructie ontbreekt, zie pp. 519-522) is niet strijdig met hypothesen als de bovenstaande, maar ze is wel een stuk grofmaziger.

Voor een tweede voorbeeld keren we nog even terug naar het krijgenpassief. Op p. 448 verwijst de SoD kort naar een bewering uit Colleman (2006), namelijk dat de krijgen-constructie zich niet laat combineren met privatieve en antidatieve werkwoorden en dat die restrictie te verklaren valt doordat de betekenis van zulke werkwoorden strijdig is met de betekenis van het zelfstandige werkwoord krijgen die blijkbaar nog doorwerkt in de passieve constructie: iemand aan wie iets wordt geweigerd of van wie iets wordt afgepakt krijgt immers helemaal niets - een typisch geval van semantische persistentie à la Hopper (1991) dus, al wordt die term in Colleman (2006) nog niet gebruikt. De $S o D$ betwijfelt die voorstelling: privatieve werkwoorden als ontnemen en dergelijke zijn inderdaad uitgesloten, maar voor antidatieve werkwoorden zoals weigeren en ontzeggen blijken op het Internet wel degelijk makkelijk voorbeelden van het krijgen-passief te vinden en de geraadpleegde informanten maken tegen die voorbeelden geen bezwaar (p. 448). Daarmee is natuurlijk nog niet gezegd dat zulke voor- 
beelden ook gebruikelijk zijn. Ter illustratie: een automatische zoekopdracht in een sample van 200 miljoen woorden tekst uit de jaargangen 1998 tot 2002 van het Twente Nieuws Corpus naar alle contexten waarin een van de voltooid deelwoorden geweigerd, ontzegd, belet en bespaard gecombineerd wordt met een vorm van het werkwoord krijgen binnen een afstand van maximaal zeven woorden naar links of naar rechts, levert precies één voorbeeld van het krijgen-passief op, met het werkwoord ontzeggen. Werkwoorden als toewijzen en aanbieden komen in het journalistieke taalgebruik ongeveer tien keer voor in de krijgen-constructie per één miljoen woorden tekst, dus zulke zinnen zijn ongeveer tweeduizend keer zo frequent als krijgen-zinnen met ontzeggen e.d. (zie Colleman 2015 voor de details). Kortom, de Internetvoorbeelden die in de $S o D$ worden aangehaald mogen dan al aantonen dat het oordeel in Colleman (2006) wat te streng was geformuleerd, feit blijft dat krijgen-zinnen met antidatieve werkwoorden erg infrequent zijn, en dat is evenzeer een relevante observatie: er is misschien geen categorische, maar zeker wel een statistische restrictie (zie daarover bijvoorbeeld Stefanowitsch 2006). Merk ook op dat de observatie dat het krijgen-passief zich nog net iets beter (of beter gezegd, iets minder slecht) laat combineren met antidatieve dan met privatieve werkwoorden an sich niet strijdig is met een verklaring in termen van semantische persistentie: de persoon aan wie iets wordt geweigerd is immers in tegenstelling tot de persoon van wie iets wordt afgepakt wel degelijk een ontvanger, zij het dan de ontvanger van een geblokkeerde overdracht.

\section{$4 \quad$ Van echte en schijnbare alternanties}

Paragraaf 3.4 is gewijd aan een aantal fenomenen die volgens de auteurs minder aanspraak kunnen maken op de status van werkwoordalternantie, zoals de variatie tussen Jan trouwt vandaag met Marie en Jan en Marie trouwen vandaag. De reden waarom het hier een 'schijnbare' werkwoordalternantie betreft, is dat de met-PP in de eerste constructie volgens de auteurs geen complement van het werkwoord is, maar een adjunct. De SoD hanteert namelijk een strikte definitie van de notie werkwoordalternantie: 'Verb frame alternations involve changes in the number and the types of complements selected by the verb' (p. 591). Op de specifieke casus van de reciproke alternantie ga ik hier niet verder in: over de syntactische status van de met-groep bij werkwoorden als trouwen, praten, bespreken, enzovoort heb ik elders al gediscussieerd met de hoofdauteur, zie Broek- 
huis (2014) en Colleman (2014) en de eerdere publicaties waarnaar daarin verwezen wordt. Wel wil ik er in dit bestek op wijzen dat door die enge definitie van werkwoordalternanties nog allerlei andere interessante gevallen van syntactische variatie volledig buiten beeld blijven. Denk bijvoorbeeld aan de variatie tussen de zgn. weg-constructie in (6a) en de zichverplaatsingsconstructie in (6b) die wordt gesignaleerd in Verhagen (2003).

(6) a. Tim worstelde zich een weg door de Syntax of Dutch.

b. Tim worstelde zich door de Syntax of Dutch.

In Verhagens constructiegrammaticale optiek gaat het hier om twee onafhankelijke argumentstructuurconstructies, die verschillen naar de vorm de $w e g$-constructie is een ditransitieve structuur met een reflexief indirect object en het vaste element een weg op de direct object-plaats plus een PPcomplement terwijl de zich-verplaatsingsconstructie enkel een reflexief object en een PP heeft - maar die qua betekenis dicht bij elkaar aanleunen: allebei kunnen ze worden ingezet om allerlei gebeurtenissen te benoemen waarin een agens zich verplaatst over een letterlijk of (zoals in 6) figuurlijk pad. De variatie tussen (6a) en (6b) is niet fundamenteel verschillend van de datiefalternantie: ook daar betreft het immers, volgens een constructionele benadering, twee afzonderlijk opgeslagen argumentstructuurconstructies, met elk hun eigen formele en semantische eigenschappen, die echter een gedeeltelijk overlappend semantisch bereik hebben (d.w.z., zowel de dubbelobjectconstructie als de aan-constructie kunnen, onder meer, gebruikt worden om diverse subtypes van bezitsoverdracht te benoemen). Voor de $S o D$ echter zou de datiefalternantie wel maar de variatie in (6) niet als alternantie mogen gelden, omdat noch het reflexivum, noch de PP, noch het element een weg geselecteerd worden door het werkwoord worstelen. Zulke fenomenen zijn vanuit syntactisch oogpunt niet interessant, dixit de conclusie van paragraaf 3.4 op p. 595. In die enge afbakening van het fenomeen alternantie toont zich duidelijk de strikt projectionele visie van de $S o D$ op argumentstructuur: argumenten kunnen enkel geselecteerd worden door het zinswerkwoord (of door een secundair predikaat). De constructiegrammatica hanteert een veel minder restrictieve visie waarin ervan wordt uitgegaan dat argumenten ook kunnen worden ingebracht door de argumentstructuurconstructie zelf en dus niet hoeven te corresponderen met een lexicale rol van het zinswerkwoord (zie bv. Goldberg 2002 over de verschillende routes naar argumentstatus). Dat betekent dat we van een argumentstructuuralternantie mogen spreken zodra de grammatica twee (of meer) verschillende sjablonen - bestaande uit een 
slot voor het werkwoord en een of meer argumentplaatsen - ter beschikking stelt voor de benoeming van een bepaald type gebeurtenissen of situaties, of op die argumentplaatsen nu participanten terechtkomen waarvan het aannemelijk is te veronderstellen dat ze worden geselecteerd door het werkwoord of niet.

\section{Tot slot}

Dit stuk ligt in de lijn van eerdere besprekingsartikelen zoals Van de Velde (2014) en Beliën (2014), in die zin dat op een aantal lacunes in de grammaticale beschrijving van de $S o D$ wordt gewezen die samenhangen met de keuze van de auteurs om zich vooral te richten op de formele taaltheoretische literatuur. Het gezegde dat hoge bomen veel wind vangen is hier van toepassing: het kan niet voldoende beklemtoond worden dat de SoD een rijk naslagwerk is waarmee de taalkundige neerlandistiek zich in de handen mag wrijven. Tegelijk mag duidelijk zijn dat de beschrijving van verbale alternanties er op een aantal vlakken heel anders zou hebben uitgezien als meer plaats was ingeruimd voor de inzichten die het cognitieve, functionele en constructionele onderzoek van de laatste paar decennia heeft opgeleverd. Vooral heb ik met de hierboven aangeroerde kwesties willen onderstrepen dat die alternatieve benaderingen meer oog hebben voor allerlei graduele onderscheidingen en voor vaagheid in de afbakening van grammaticale fenomenen: er is geen dichotomie tussen productieve en idiosyncratische constructies, er zijn betekenisvolle gradaties van ongebruikelijkheid en argumenten kunnen maar hoeven niet door het werkwoord te worden geselecteerd. Ik hoop dat sommige van die inzichten later hun weg mogen vinden naar de geamendeerde en vervolmaakte grammaticale beschrijving die in Broekhuis (2013) in het vooruitzicht wordt gesteld, als een belangrijke vervolgstap voor het Taalportaal-project na de publicatie van de verschillende boekdelen van de $S o D$. De afronding van die eerste fase is met de publicatie van de monumentale VP-trilogie alweer een flinke stap dichterbij gekomen. 


\section{Referenties}

Beliën, M. (2014). Complementing Adpositions and adpositional phrases: a review of Broekhuis (2013). Nederlandse Taalkunde 19, 291-304.

Bolinger, D. (1977). Meaning and form. London: Longman.

Broekhuis, H. (2013). De Syntax of Dutch: nieuw gereedschap voor de internationale neerlandistiek. Internationale Neerlandistiek 51, 243-259.

Broekhuis, H. (2014). Dubbel-voorzetselobjectconstructies? In: F. Van de Velde et al. (red.), $P a$ troon en argument. Een dubbelfeestbundel bij het emeritaat van William van Belle en Joop van der Horst. Leuven: Universitaire Pers Leuven, 103-113.

Broekhuis, H. \& L. Cornips (1994). Undative constructions. Linguistics 32, 173-189.

Broekhuis, H. \& L. Cornips (2012). The verb krijgen 'to get' as an undative verb. Linguistics 50, 12051249 .

Broekhuis, H., N. Corver \& R. Vos (2015). Syntax of Dutch. Verbs and Verb Phrases: Volume I. Amsterdam: Amsterdam University Press.

Bybee, J. (2010). Language, Usage and Cognition. Cambridge: Cambridge University Press.

Colleman, T. (2006). De Nederlandse datiefalternantie: Een constructioneel en corpusgebaseerd onderzoek. Proefschrift Universiteit Gent.

Colleman, T. (2009). Verb disposition in argument structure alternations: A corpus study of the Dutch dative alternation. Language Sciences 31, 593-611.

Colleman, T. (2010). Lectal variation in constructional semantics: 'Benefactive' ditransitives in Dutch. In: D. Geeraerts, G. Kristiansen \& Y. Peirsman (red.), Recent Advances in Cognitive Sociolinguistics. Berlin: Mouton de Gruyter, 191-221.

Colleman, T. (2014). Nog eens de dubbel-voorzetselobjectconstructie. In: F. Van de Velde et al. (red.), Patroon en argument. Een dubbelfeestbundel bij het emeritaat van William van Belle en Joop van der Horst. Leuven: Universitaire Pers Leuven, 115-127.

Colleman, T. (2015). Constructionalization and post-constructionalization: The constructional semantics of the Dutch krijgen-passive in a diachronic perspective. In: J. Barðdal et al. (red.), Diachronic Construction Grammar. Amsterdam \& Philadelphia: John Benjamins, 215-258.

Colleman, T. \& D. Rens (2016). Het krijgen-passief en de werkwoordelijke eindgroep: Een diachrone voorstudie op basis van Delpher. Studies van de Belgische Kring voor Linguïstiek 10. <http://www.bkl-cbl.be/>

Divjak, D. \& S.Th. Gries (red.) (2012). Frequency effects in language. Volume 2: Frequency effects in language representation. Berlin: Mouton de Gruyter.

Goldberg, A.E. (2002). Surface generalizations: An alternative to alternations. Cognitive Linguistics $13,327-356$.

Hopper, Paul (1991). On some principles of grammaticalization. In: E.C. Traugott \& B. Heine (red.), Approaches to Grammaticalization. Amsterdam \& Philadelphia: John Benjamins, 17-35.

Hout, A. van (1996). Event semantics of verb frame alternations: A case study of Dutch and its acquisition. Proefschrift Katholieke Universiteit Brabant, Tilburg.

Rappaport Hovav, M. \& B. Levin (2008). The English dative alternation: The case for verb sensitivity. Journal of Linguistics 44, 129-167.

Stefanowitsch, A. (2006). Negative evidence and the raw frequency fallacy. Corpus Linguistics and Linguistic Theory 2, 61-77.

Van de Velde, F. (2014). Nederlandse predeterminatoren als levend fossiel. Nederlandse Taalkunde 19, 87-103.

Verhagen, A. (2003). Hoe het Nederlands zich een eigen weg baant: Vergelijkende en historische observaties vanuit een constructie-perspectief. Nederlandse Taalkunde 8, 328-346. 
NEDERLANDSE TAALKUNDE

About the author

Timothy Colleman, Universiteit Gent

E-mail: timothy.colleman@UGent.be 